\title{
Estrogen Establishes Sex Differences in Androgen Accumulation in Zebra Finch Brain
}

\author{
K. W. Nordeen, E. J. Nordeen, and A. P. Arnold \\ Department of Psychology and Laboratory of Neuroendocrinology, Brain Research Institute, \\ University of California, Los Angeles, Los Angeles, California 90024
}

In zebra finches, androgens stimulate the production of a learned courtship song in males but not in females. Corresponding to this behavioral dimorphism, neural regions controlling the learning and production of song are much larger in males than in females. In two of these song-related brain regions, magnocellular nucleus of the anterior neostriatum (MAN) and hyperstriatum ventrale pars caudale (HVc), males have a larger percentage of androgen-accumulating cells than females. Since sex differences in the capacity for song and in the size of songrelated nuclei are established by gonadal hormones shortly after hatching, we determined whether the early hormonal environment also establishes sex differences in androgen accumulation within MAN and HVc. Newly hatched female zebra finches received either estradiol (E2) or cholesterol $(\mathrm{Ch})$. Three to six months later, E2-females, Ch-females, and normal adult males were gonadectomized and injected $24 \mathrm{hr}$ later with ${ }^{3} \mathrm{H}$-dihydrotestosterone. Autoradiograms were prepared, and the incidence of androgen-labeled cells was determined for MAN, HVc, and a control region, the lateral septal nucleus (SL).

In females, early $\mathbf{E} 2$ exposure dramatically increases the percentage of androgen-accumulating cells in MAN and HVc, without influencing androgen accumulation in SL. In MAN and $\mathrm{HVc}$, the percentage of androgen-concentrating cells in E2-females approximates that observed in normal adult males. Cells also tended to be more densely labeled in E2-females than in Ch-females. Since early E2 exposure renders the female song system neuroanatomically and functionally responsive to androgens, we suggest that $\mathrm{E} 2$ establishes this responsiveness by regulating the number of androgen target neurons within MAN and HVc.

In several species of passerine birds, males and females differ in their ability to produce song. In zebra finches (Poephila guttata), this behavioral dimorphism is extreme. In response to circulating gonadal androgens, adult male zebra finches produce a highly stereotyped courtship song learned from their fathers during development (Arnold, 1975; Immelmann, 1969; Pröve, 1974). Adult females do not sing, even if provided with exogenous androgens. Sex differences in vocal ability are associated with large sex differences in the organization of brain regions that control song learning and production. This neural system includes motoneurons innervating the syringeal musculature and a series of midbrain and telencephalic nuclei. All of these nuclei are larger in males than in females (Nottebohm and Arnold,

Received Mar. 11, 1985; revised June 13, 1985; accepted June 14, 1985.

This work was supported by USPHS Grant HD15021 and NSF Grant BNS 8006798.

Correspondence should be addressed to Kathy W. Nordeen at her current address: Department of Psychology, University of Rochester, Rivcr Campus, Rochester, NY 14627.

Copyright $@ 1986$ Society for Neuroscience $0270-6474 / 86 / 030734-05 \$ 02.00 / 0$
1976), and, in most of these regions, neurons are larger and more numerous in males than in females (Arnold, 1980; Gurney, 1981; Konishi and Gurney, 1982).

Another sex difference corresponding to the differential ability of androgens to induce song in males but not in females is in the number of androgen target cells in song-related brain regions. Most song regions contain cells that selectively accumulate radioactivity following injections of the androgen testosterone (T) or its androgenic metabolite, dihydrotestosterone (DHT) (Arnold, 1979; Arnold and Saltiel, 1979; Arnold et al., 1976). In two of these regions, magnocellular nucleus of the anterior neostriatum (MAN) and hyperstriatum ventrale pars caudale $(\mathrm{HVc})$, male zebra finches have a greater number of androgen target cells than females (Arnold and Saltiel, 1979). The region HVc is part of the motor pathway mediating song production, and lesioning this area in canaries severely disrupts adult song (Nottebohm et al., 1976). Neurons in MAN, however, may be specifically involved in vocal learning, since lesions of this area in juvenile male zebra finches disrupt song development, whereas lesions in adulthood have no effect on the production of fully developed song (Bottjer et al., 1984). In zebra finches, song production and possibly song learning are dependent on androgens. Since steroids are presumed to act through cellular mechanisms involving the selective accumulation and retention of steroid within cells (McEwen, 1979), the sex difference in androgen accumulation within MAN and HVc may underlie sex differences in the behavioral response to androgens.

Sex differences in the capacity for male-typical song and in the anatomy of song-related brain regions are established by the early hormonal environment. If female zebra finches are given $\mathrm{T}$ or its active metabolite, estradiol (E2), shortly after hatching, these females will produce male-typical song if treated with androgens in adulthood. This early exposure to E2 partially masculinizes the morphology of song-related brain regions and, importantly, renders them anatomically sensitive to later androgen treatment (Gurney, 1981, 1982; Gurney and Konishi, 1980). Unlike normal adult females, neonatally estrogenized females respond to $\mathrm{T}$ or its androgenic metabolite DHT with dramatic neural growth throughout the song system (Gurney, 1980; Gurney and Konishi, 1980). This androgen-induced neural growth is coincident with the development of song. Thus, early E2 exposure provides a neural substrate for song that is both morphologically and functionally sensitive to later androgenic stimulation. E2 may enhance the androgenic sensitivity of the song system by increasing the number of androgen target cells within MAN and HVc. With this in mind, we compared the percentage of cells accumulating DHT or its metabolites in these song regions in normal adult females and in adult females treated with E2 on the day of hatching. We report here that early E2 treatment significantly increases, or masculinizes, the extent of androgen accumulation in MAN and HVc. 


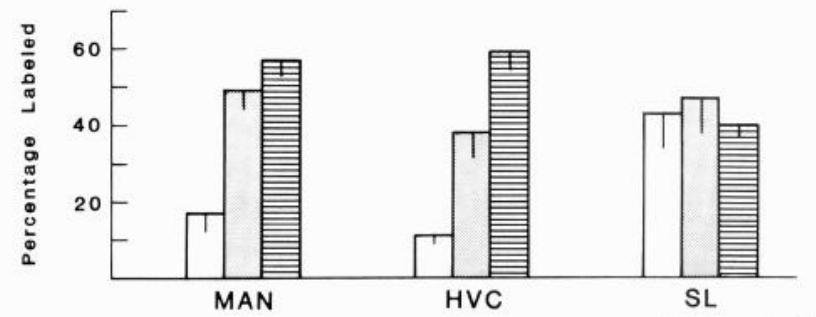

Figure 1. Percentage of cells accumulating ${ }^{3} \mathrm{H}-\mathrm{DHT}$ or its metabolites in MAN, HVc, and SL. Histograms represent means \pm SEM for Chfemales ( $\square$ ), E2-females ( $\square$ ), males (目). Early E2 treatment in females significantly increases the percentage of labeled cells in MAN and HVc.

\section{Materials and Methods}

On the day of hatching, female zebra finches received subcutaneous implants of Silastic ropes $(1 \mathrm{~mm})$ impregnated with either $25 \mu \mathrm{g}$ of E2 or cholesterol $(\mathrm{Ch})$. The ropes were prepared as described by Gurney and Konishi (1980), except that we used a 1:11 mixture (by weight) of steroid and medical-grade Silastic (Dow Corning). Under in vivo conditions in adults, this type of implant releases most ( $>85 \%)$ of its E2 within $10 \mathrm{~d}$ after implantation (Gurney, 1980). Following steroid implantation, chicks were housed with their parents until adult. At 3-6 months of age, three normal males, four E2-treated females, and four Ch-treated females were gonadectomized, and implants were removed. The following day, each bird was injected intramuscularly with $20 \mathrm{ng} /$ gm body weight of tritiated DHT (New England Nuclear; specific activity $=135-143 \mathrm{Ci} / \mathrm{mmol}$, total $\mu \mathrm{Ci}$ dose $=93-138)$. The animals were killed $90 \mathrm{~min}$ after injection, and the brain was quickly removed and frozen in dry ice. Coronal sections $(6 \mu \mathrm{m})$ were cut in a cryostat and mounted on microscope slides previously dipped in Kodak NTB-3 nuclear track emulsion. Reference sections $(18 \mu \mathrm{m})$ were taken every $65 \mu \mathrm{m}$, mounted onto gelatin-coated slides, and stained with thionin. The autoradiograms were stored in desiccated dark containers at $4^{\circ} \mathrm{C}$ for 4,6 , or 8 weeks and then developed in Kodak D-19. The tissue was fixed in formalin and stained with thionin.

The autoradiograms were analyzed under a bright-field microscope with the aid of a camera lucida. The boundaries of MAN and HVc were first defined using the reference sections. In Ch-females, where MAN is difficult to discern in reference sections, the presence of labeled cells in autoradiograms was also used to identify this nucleus. Autoradiograms containing the central (rostrocaudal) third of MAN and HVc were chosen for quantification. At least 150 cells per animal were analyzed for each of these regions. We also analyzed 75 cells per animal within an area outside of the song system, the lateral septal nucleus (SL). The perimeters of cells were drawn and the number of silver grains over each cell and over an adjacent unstained area of neuropil $(>10 \times$ average cell area) were counted. Cells were analyzed only if a limiting membrane was apparent. Each cell was drawn onto a digitizing tablet interfaced with a computer; the area of the cell was calculated; and an expected grain count was calculated as the background grain density of the neuropil, multiplied by the cell area. Quantitative criteria based on the Poisson distribution were used to determine if a cell was labeled (Arnold, 1980). The expected count was used as a mean of a Poisson distribution, and a cell was considered labeled if the actual grain count equaled or exceeded the $99 \%$ confidence interval limit for that Poisson distribution. A two-tailed, one-way analysis of variance was used for all statistical comparisons.

\section{Results}

In both MAN and HVc, there is a smaller percentage of androgen-accumulating cells in females than in males, and the extent of androgen accumulation in these regions is increased in females following early E2 treatment. As shown in Figure 1, the percentage of MAN cells accumulating ${ }^{3} \mathrm{H}-\mathrm{DHT}$ or its metabolites in Ch-females $(17 \%)$ is significantly less $(F=35.9, d f=$ $1,8, p<0.001)$ than in either E2-females $(49 \%)$ or males $(57 \%)$. Moreover, E2-females do not differ significantly from males in the percentage of androgen-accumulating cells in MAN ( $F=$ $1.2, d f=1,8, p>0.10$ ). Also, in $\mathrm{HVc}$, the incidence of androgenlabeled cells in Ch-females (11\%) is significantly less than in
Table 1. Sex differences and the influence of early estrogen exposure on cell size and androgen accumulation in MAN and $\mathrm{HVc}$

\begin{tabular}{lllc} 
& $\begin{array}{l}\text { Percentage } \\
\text { labeled }\end{array}$ & $\begin{array}{l}\text { Density ratio } \\
\text { (labeled cells) }\end{array}$ & $\begin{array}{c}\text { Overall } \\
\text { cell size }\end{array}$ \\
\hline MAN & & & \\
Ch-female & $17 \pm 5$ & $2.8 \pm 0.2$ & $83 \pm 4$ \\
E2-female & $49 \pm 5$ & $6.5 \pm 1.0$ & $85 \pm 20$ \\
Male & $57 \pm 4$ & $3.7 \pm 0.7$ & $168 \pm 10$ \\
HVc & & & \\
Ch-female & $11 \pm 2$ & $3.5 \pm 0.6$ & $53 \pm 4$ \\
E2-female & $38 \pm 6$ & $5.0 \pm 1.0$ & $60 \pm 2$ \\
Male & $59 \pm 5$ & $4.7 \pm 1.7$ & $113 \pm 5$ \\
\hline
\end{tabular}

Data shown are the percentages of androgen-accumulating cells in MAN and $\mathrm{HVC}$ as well as their intensity of labeling (density ratio = grain density over cell/ background grain density). Also shown is the overall mean cell size (labeled and unlabeled) in MAN and HVc. Numbers represent means \pm SEM. Early E2 treatment in females increases both the percentage and density ratio of labeled cells in MAN and $\mathrm{HVc}$, without influencing overall cell size.

either E2-females (39\%) or males (59\%; $F=39.7, d f=1,8, p<$ $0.001)$. However, in this region, E2-females have slightly, but significantly, less labeling than males $(F=7.7, d f=1,8, p<$ $0.05)$. Early E2 treatment of females does not influence the extent of androgen accumulation within $\operatorname{SL}(F=0.25, d f=1,8$, $p>0.10)$, a region that normally shows no sex difference in the percentage of androgen-accumulating cells.

In HVc, neonatally estrogenized females have at least as many cells as do normal females (Konishi and Gurney, 1982). Although similar data on cell number in MAN are lacking, measurements of this nucleus, taken from reference sections and autoradiograms, indicate that MAN is much larger in E2females than in Ch-females, without any obvious difference in cell density (personal observations). These data suggest that differences between these groups in the percentage of androgenaccumulating cells must reflect differences in the number of such cells. Sex differences and E2's influence on androgen accumulation can be seen in photomicrographs of autoradiograms (Fig. 2). Since the ability to detect labeled cells might be influenced by the background grain density, it is important that the density of silver grains over background neuropil did not differ significantly across groups in any of the regions examined $(F<2.5$, $d f=1,8, p>0.10)$.

Early E2 exposure also increases the intensity of labeling over androgen-accumulating neurons in MAN and HVc. These data are reflected in the density ratio, which is the silver grain density over a cell divided by the background silver grain density (or actual silver grain count/expected grain count). As shown in Table 1 , the density ratio for labeled MAN cells is significantly higher in E2-females than in Ch-females $(F=13.7, d f=1,8$, $p<0.01$ ). Within $\mathrm{HVc}$, the overall mean intensity of labeling is also greater in E2-females than in Ch-females; however, this difference is not statistically significant $(F=1.66, d f=1,8, p>$ 0.10 ). The density ratio of labeled MAN cells is lower in males than in E2-females, probably reflecting the larger size of these cells in males.

Although males have larger cells than females in both MAN and $\mathrm{HVc}$, the dose of $\mathrm{E} 2 \mathrm{used}$ in this experiment did not increase cell size in females in either of these brain regions. This is evident both in comparisons of overall cell size means (Table 1) and in the frequency distribution of cell sizes (Fig. 3). Qualitative observations, however, indicate that the overall volume of MAN and $\mathrm{HVc}$ is larger in males and E2-females than in Ch-females. This may reflect differences in cell density and/or cell number.

Figure 3 illustrates the percentage of cells labeled in each size class. In virtually every size class within both MAN and $\mathrm{HVc}$, 
FEMALE
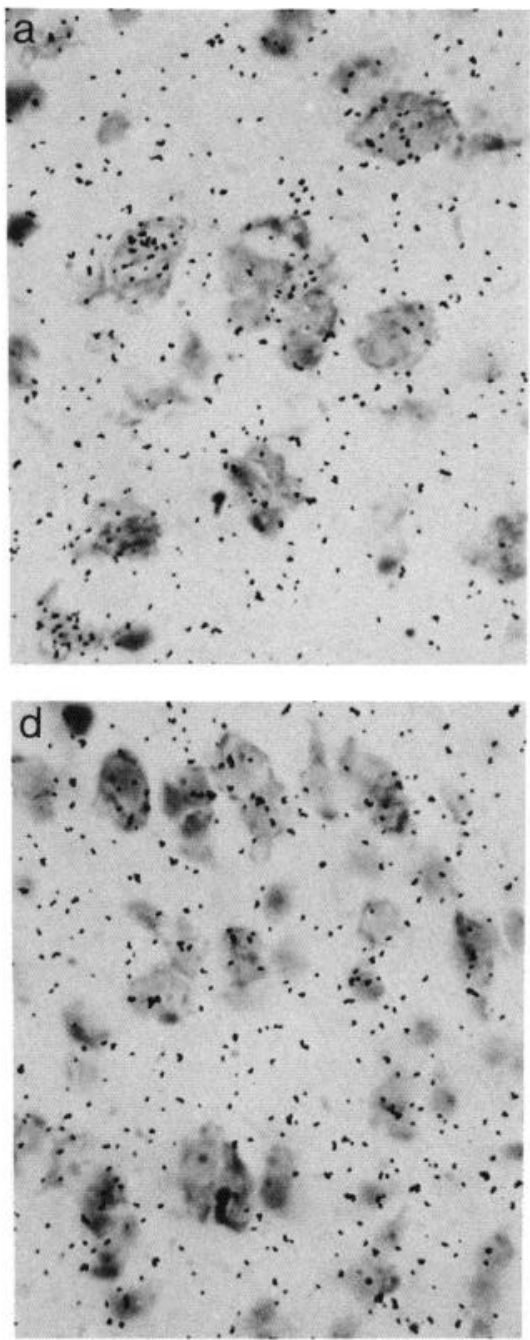

E2-FEMALE
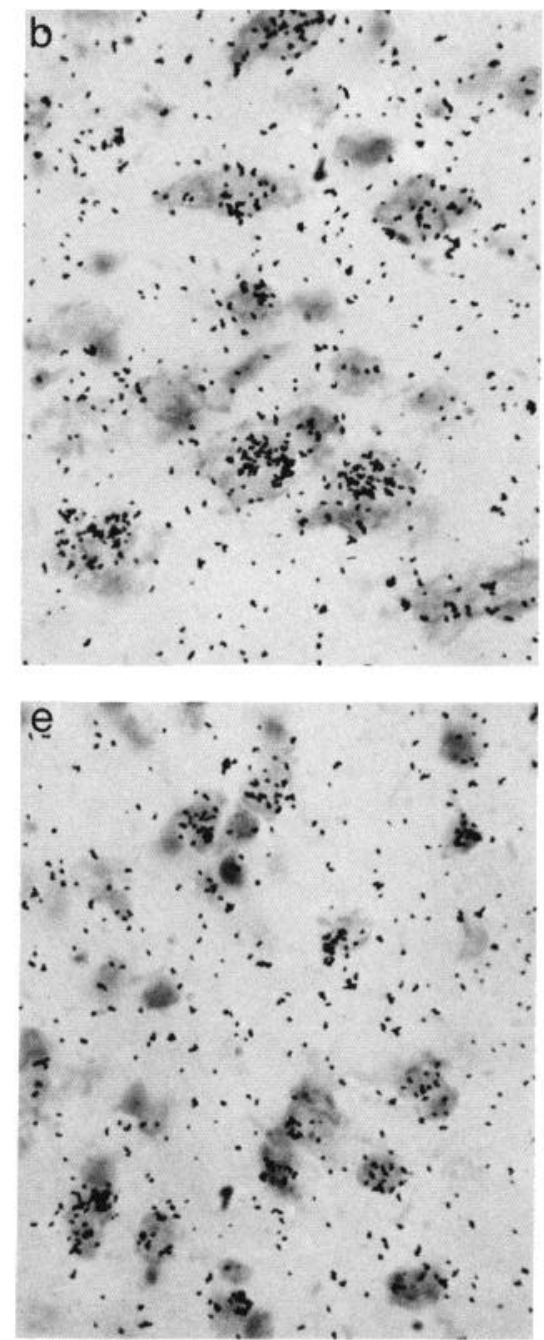

MALE
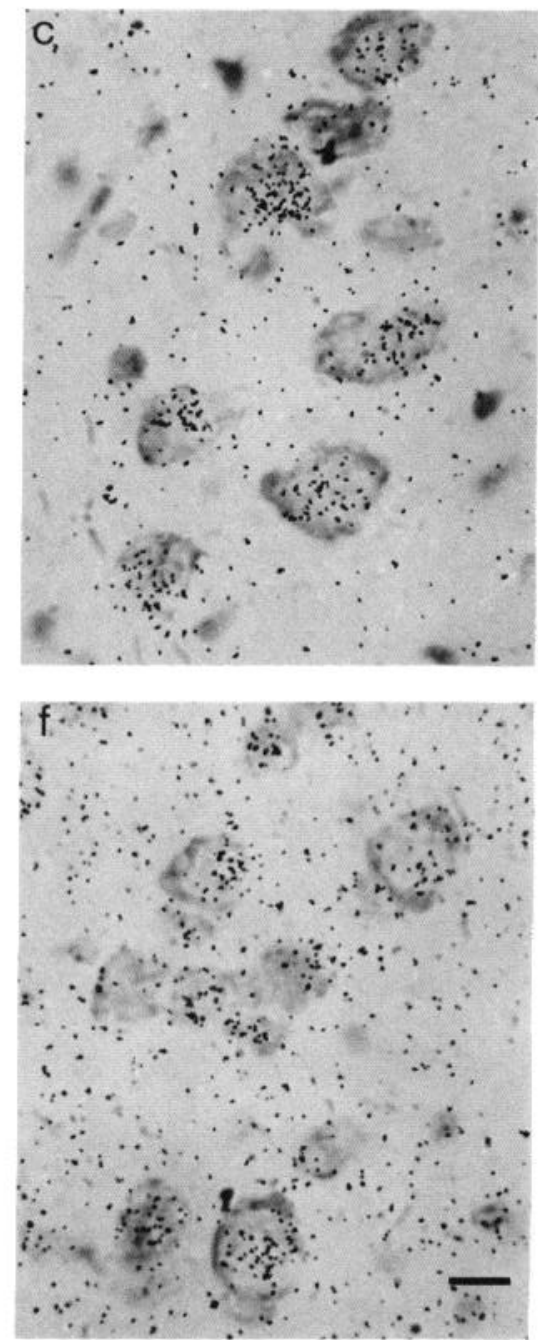

Figure 2. Photomicrographs of autoradiograms taken in MAN and HVc. $a$, Ch-female MAN, $b$, E2-female MAN, $c$, male MAN, $d$, Ch-female $\mathrm{HVc}, e$, E2-female HVc, and $f$, male HVc. Labeled cells in MAN and HVc of E2-females are more frequent and more heavily labeled than in Chfemales. In both brain regions, the frequency of labeled cells is similar in males to that in E2-females. Calibration bar, $10 \mu \mathrm{m}$.

there is a greater percentage of androgen-accumulating cells in E2-females than in $\mathrm{Ch}$-females. In all groups, large cells in MAN are more likely to be labeled than small cells. In HVc, there was no consistent relationship between cell size and probability of labeling. In $\mathrm{Ch}$ - and E2-females, labeled cells in HVc do not differ significantly in size from unlabeled cells. However, in males, labeled HVc cells are larger than unlabeled cells in overall mean size.

\section{Discussion}

In female zebra finches, exposure to E2 shortly after hatching profoundly increases the percentage of androgen-accumulating cells in MAN and $\mathrm{HVc}$, two brain regions implicated in the control of song learning and production. In this species, sex differences in the number of androgen-accumulating cells parallel sex differences in vocal ability (Arnold and Saltiel, 1979). Since early exposure to E2 determines the capacity for androgendependent song (Gurney and Konishi, 1980), it is likely that E2 establishes behavioral sensitivity to androgens by regulating the number of androgen target neurons in the song system.

In mammals, the sexual differentiation of reproductive be- havior and neuroendocrine function is also associated with estrogenic regulation of hormonal sensitivity. In rodents, perinatal exposure to $\mathrm{T}$ or its metabolite E2 reduces E2 binding to specific hypothalamic nuclei and reduces E2 sensitivity with regard to female sexual behavior and neuroendocrine function (Nordeen and Yahr, 1983; Rainbow et al., 1982). Our results show that, in zebra finches, early E2 exposure can also increase the extent of steroid accumulation, thus providing a neural correlate for masculinization, that is, the increased propensity to show maletypical behavior in response to gonadal hormones.

Estrogen could increase the number of steroid-accumulating cells detected within MAN and HVc either by increasing the availability of steroid or by increasing the affinity and/or number of steroid receptors within these regions. Since E2's influence on androgen accumulation is specific to MAN and HVc (i.e., E2 does not influence androgen accumulation in SL), it is unlikely that the mechanism of E2 action involves generalized changes in peripheral metabolism or availability of hormone. In addition, recent biochemical studies indicate that in female zebra finches, early E2 exposure increases the concentration of androgen cytosol receptors within the forebrain without influ- 

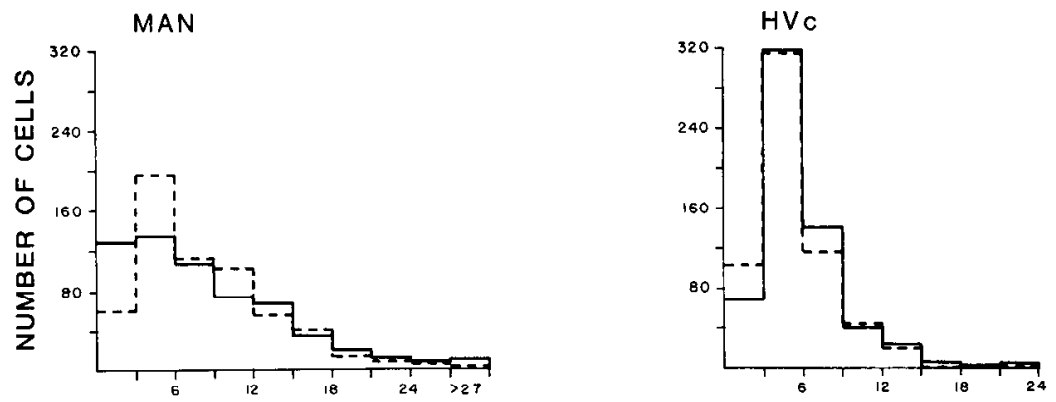

SIZE CLASS $\left(\mathrm{um}^{2} \times 10\right)$
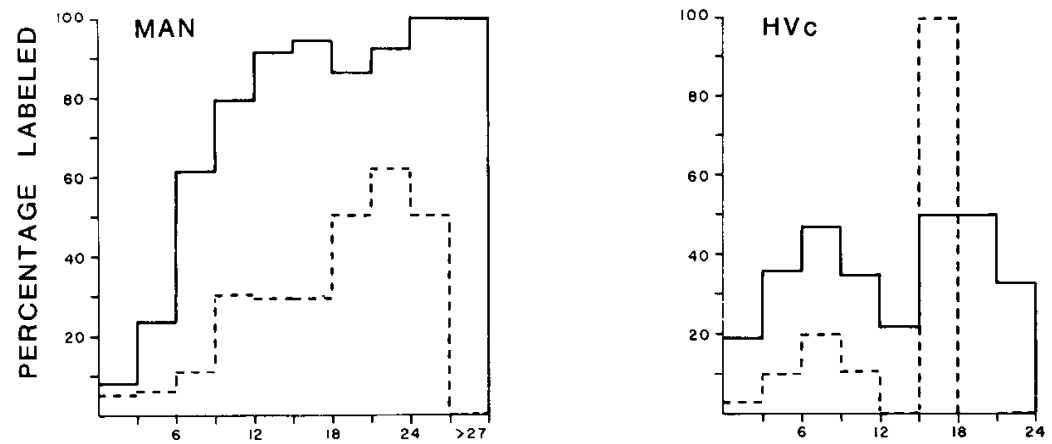

SIZE CLASS $\left(u m^{2} \times 10\right)$

Figure 3. Top, Cell size distributions for MAN and HVc in Ch-females (dotted lines) and E2-females (solid lines). For each brain region, a total of 600 cells was sampled in each group. Bottom, Percentage of cells labeled in MAN and $\mathrm{HV} c$ according to size class in $\mathrm{Ch}$ females (dotted lines) and E2-females (solid lines). For each group, the number of labeled cells in each size class is expressed as a percentage of the total number of cells sampled in that size class. encing their affinity characteristics (Siegel et al., 1985). These observations suggest that the increase in the number of androgen-accumulating cells in MAN and $\mathrm{HVc}$ reflects an increase in the number of androgen receptors within these areas.

It is not known how sex differences in androgen accumulation normally develop within the song system, and hence what cellular processes are regulated by E2 to establish a masculine pattern of steroid accumulation. One possibility is that E2 preserves a masculine number of androgen target cells that are normally present in early development. In this case, E2 might either enhance the survival of androgen-accumulating cells or preserve their ability to accumulate androgens. Alternatively, E2 may induce a masculine pattern of androgen accumulation not normally present in developing song regions. E2 may induce androgen receptors within cclls or enhance the proliferation or survival of newly generated androgen-accumulating cells. Although we cannot yet distinguish among these alternatives, our data do provide some insight into the possible mechanisms of E2 action. For example, to the extent that different functional classes of neurons can be discriminated on the basis of their size, our data are inconsistent with the idea that E2 influences androgen accumulation by producing or preserving one specific neuronal class. The overall cell size distribution in MAN and $\mathrm{HVC}$ does not differ between E2- and Ch-females, and E2 increases the percentage of labeled cells present in each size class. However, our data are consistent with the possibility that E2 influences the number of androgen receptors within cells. The greater density ratio of labeled cells in MAN of E2-females, as compared to $\mathrm{Ch}$-females, suggests that $\mathrm{E} 2$ not only increases the number of androgen target neurons, but also increases the extent to which they accumulate hormone.

Gurney (1982) has reported that early E2 treatment can also masculinize the morphology of MAN and $\mathrm{HVc}$, as well as other song-related regions. To understand better the cellular mecha- nisms underlying sexual differentiation, it is important to establish the relationship between these E2-induced anatomical changes and the changes in androgen accumulation reported here. One anatomical change that can be produced by E2 is an increase in the size of neurons within HVc and MAN. Our results show that this aspect of morphological masculinization is independent of changes in androgen accumulation within these regions, since the low dose of $\mathrm{E} 2$ used in the present experiment increased androgen accumulation without increasing cell size. Nconatally cstrogenized females also have more cclls than do normal females in some song regions (Gurney, 1982; M. Konishi, personal communication), and this aspect of morphological masculinization may be related to E2's effect on the number of androgen target cells in MAN and HVc. If, for example, E2 increases cell number in HVc and MAN by enhancing the survival of androgen-accumulating cells in these regions, then E2 effects on cell number and androgen accumulation would involve a common cellular mechanism.

One way that E2's influence on androgen accumulation could contribute to the capacity for male-typical song is by providing the substrate necessary for later neural and behavioral plasticity. As a result of early E2 exposure, the adult zebra finch song system is capable of tremendous neural growth in response to androgenic stimulation. Although it is not yet known if this growth is associated with synaptic reorganization in zebra finches, androgens do induce dendritic growth and synaptogenesis in adult female canaries (DeVoogd and Nottebohm, 1981; DeVoogd et al., 1982, 1983). It may be, as Nottebohm (1981) has suggested, that such synaptic plasticity is necessary for vocal learning. Causal relationships between androgen-induced neural growth and vocal development are not yet established, but this growth is coincident with song learning in both zebra finches and canaries. Female zebra finches may be unable to produce song because they lack the capacity for androgen-induced neural 
growth, a limitation imposed by the paucity of androgen target cells in MAN and HVc.

The hypothesis that E2 establishes the androgenic sensitivity of the song system through its influence on androgen target cells in MAN and HVc suggests a resolution to a paradox concerning the neural site(s) of androgen action in the adult zebra finch brain. In neonatally estrogenized females, androgens promote neural growth throughout the adult song system, yet song regions vary considerably in their ability to accumulate androgens. For example, one song region, Area $X$, can double its volume in response to androgens (Gurney, 1982), yet does not contain androgen-accumulating neurons (Arnold et al., 1976, and unpublished observations). To reconcile this with the prevailing notion that steroids exert their effects by interacting with hormone-accumulating target neurons, it is necessary to postulate that androgens exert their effects on Area X indirectly, by initiating changes elsewhere in the brain. Since Area $X$ receives a substantial projection from HVc (Gurney, 1981; Nottebohm et al., 1976), it is possible that androgen-induced neural growth within HVc transsynaptically induces growth and/or synaptogenesis within its afferents or efferent targets (i.e., Area X). Such transsynaptic influences between neural populations have been widely documented (see Jacobson, 1978), and through such interactions, E2's effects on androgen accumulation in MAN and HVc may establish androgenic sensitivity throughout the song system. Developing this hypothesis entails knowing the projections of androgen-accumulating cells in MAN and HVc, and whether androgenic stimulation of these regions alone is suffcient to promote neural growth in other song-related brain areas. Addressing these questions will clarify the importance of cellular interactions in mediating steroid-induced structural changes, and will help localize specific pathways involved in vocal learning and production.

\section{References}

Arnold, A. (1975) The effects of castration and androgen replacement on song, courtship, and aggression in zebra finches. J. Exp. Zool. 191: 309-326.

Arnold, A. (1980) Quantitative analysis of sex differences in hormone accumulation in the zebra finch brain: Methodological and theoretical issues. J. Comp. Neurol. 189: 421-436.

Arnold, A., F. Nottebohm, and D. W. Pfaff (1976) Hormone-concentrating cells in vocal control and other areas of the brain of the zebra finch. J. Comp. Neurol. 165: 478-512.

Arnold, A. P. (1979) Hormone accumulation in the brain of the zebra finch after injection of various steroids and steroid competitors. Soc. Neurosci. Abstr. 5: 437.
Arnold, A. P., and A. Saltiel (1979) Sexual difference in pattern of hormone accumulation in the brain of a song bird. Science 205: 702705.

Bottjer, S. W., E. A. Miesner, and A. P. Arnold (1984) Forebrain lesions disrupt development but not maintenance of song in passerine birds. Science 224: 901-903.

DeVoogd, T., and F. Nottebohm (1981) Gonadal hormones induce dendritic growth in the adult avian brain. Science 214: 202-204.

DeVoogd, T. J., B. Nixdorf, and F. Nottebohm (1982) Recruitment of additional synapses into a brain network takes extra brain space. Soc. Neurosci. Abstr. 8: 140

DeVoogd, T. J., B. Nixdorf, and F. Nottebohm (1983) Steroid induced neural plasticity is multifaceted. Soc. Neurosci. Abstr. 9: 380 .

Gurney, M. (1980) Sexual differentiation of brain and behavior in the zebra finch (Peophila guttata): A cellular analysis. Ph.D. dissertation, California Institute of Technology.

Gurney, M. (1981) Hormonal control of cell form and number in the zebra finch song system. J. Neurosci. 1: 658-673.

Gurney, M. (1982) Behavioral correlates of sexual differentiation in the zebra finch song system. Brain Res. 231: 153-172.

Gurney, M., and M. Konishi (1980) Hormone induced sexual differentiation of brain and behavior in zebra finches. Science 208: 13801382.

Immelmann, K. (1969) Song development in the zebra finch and other estrildid finches. In Bird Vocalizations, R. A. Hinde, ed., Cambridge, Cambridge, UK.

Jacobson, M. (1978) Developmental Neurobiology, Plenum, New York.

Konishi, M., and M. Gurney (1982) Sexual differentiation of brain and behavior. Trends Neurosci. 5: 20-23.

McEwen, B. S., P. G. Davis, B. Parsons, and D. W. Pfaff (1979) The brain as a target for steroid hormone action. Annu. Rev. Neurosci. 2: $65-112$.

Nordeen, E. J., and P. Yahr (1983) A regional analysis of estrogen binding to hypothalamic cell nuclei in relation to masculinization and defeminization. J. Neurosci. 3: 933-941.

Nottebohm, F. (1981) A brain for all seasons: Cyclical anatomical changes in song control nuclei of the canary brain. Science 214: 13681370 .

Nottebohm, F., and A. Arnold (1976) Sexual dimorphism in vocal control areas of the song bird brain. Science 194: 211-213.

Nottebohm, F., T. M. Stokes, and C. M. Leonard (1976) Central control of song in the canary (Serinus canarius). J. Comp. Neurol. 165: 457-486.

Pröve, E. (1974) Der Einfluss von Kastration und Testosteronsubstitution auf das Verhalten männlicher Zebrafinken. J. Ornithol. 115: 338-347.

Rainbow, T. C., B. Parsons, and B. S. McEwen (1982) Sex differences in rat brain oestrogen and progestin receptors. Nature 300: 648-649. 